\title{
Unexpected depletion of plasma arachidonate and total protein in cats fed a low arachidonic acid diet due to peroxidation
}

\author{
Amy Chamberlin†, Yuka Mitsuhashił, Karen Bigley and John E. Bauer* $\ddagger$ \\ Department of Small Animal Clinical Sciences, Companion Animal Nutrition Research Laboratory, College of Veterinary \\ Medicine and Biomedical Sciences, Texas AGM University, College Station, TX 77843-4474, USA
}

(Received 13 October 2010 - Revised 16 February 2011 - Accepted 21 February 2011)

\section{Abstract}

An opportunity to investigate a low-arachidonic acid (AA) feline diet possibly related to elevated peroxide value (PV) during storage on plasma phospholipid (PL) and reproductive tissue fatty acid (FA) profiles presented itself in the present study. Cats (nine animals per group) had been fed one of three dry extruded, complete and balanced diets for $300 \mathrm{~d}$ before spaying. The diets contained adequate AA $(0.3 \mathrm{~g} / \mathrm{kg})$, similar concentration of antioxidants and were stored at ambient temperature, but differed in FA composition. The diets were designated as follows: diet A (high linoleic acid), diet B (high $\gamma$-linolenic acid) and diet C (adequate linoleic acid). Diet samples that were obtained the week before spaying revealed an elevated PV of diet A $v$. diets B and C $(135 v .5 \cdot 80$ and $2 \cdot 12 \mathrm{meq} / \mathrm{kg}$ fat, respectively). Records revealed decreased food consumption of diet A cats beginning at $240 \mathrm{~d}$ but without weight loss; thus an opportunity presented to investigate diet PV effects. Total plasma protein and PL-AA concentrations in group A were significantly decreased at 140 and $300 \mathrm{~d}$. Uterine and ovarian tissues collected at surgery revealed modest decrements of AA. Diet A was below minimum standards at $0 \cdot 015 \%$ (minimum 0.02\%), probably due to oxidation. The time at which diet A became unacceptable may have occurred between 60 and $140 \mathrm{~d}$ because plasma PL-AA was within our normal colony range (approximately 4-7\% relative) after $56 \mathrm{~d}$ of feeding. High-linoleic acidcontaining diets may be more likely to be oxidised requiring additional antioxidants. The findings suggest that reduced plasma protein in combination with plasma AA concentrations may serve as biomarkers of diet peroxidation in cats before feed refusal, weight loss or tissue depletion.

\section{Key words: Arachidonate: Peroxidised diet: Reproductive tissues: Total protein}

Because highly unsaturated fats are typically included in feline diets, diet peroxidation during storage is of concern and antioxidants are often added. Although feed refusal reportedly occurs in cats fed oxidised diets, some animals continue to eat such diets. Fats, particularly those that contain PUFA, are susceptible to rancidity. Vilas et $a l .{ }^{(1)}$ found that feeding rancid fats decreases growth rate and significantly increases the weight of the intestinal epithelial layer, possibly because of inflammation in the intestine. Absorption of lipid hydroperoxides from rancid fat is questionable. Some studies have supported that reactive metabolites of the oxidised fats or fatty acids (FA) are reduced by antioxidant enzymes, such as glutathione peroxidase, in the intestinal epithelial cells ${ }^{(2)}$, while other studies have shown lipid hydroperoxides in chylomicrons $^{(3)}$ which reached the liver and caused impaired antioxidant defence of the liver cells ${ }^{(4)}$. However, severity of liver damage depends on the fat content of the diet ${ }^{(5)}$.
Rats fed a diet containing peroxidised oil with a peroxide value (PV) of approximately $90 \mathrm{meq} / \mathrm{kg}$ at a $10 \%$ level for 4 weeks had altered intestinal absorptive function. The rate of in vitro absorption of nutrients, especially sucrose and protein hydrolysate (amino acids), was considerably reduced in this species, although absorption of glucose, fructose and $\mathrm{Ca}^{2+}$ was only marginally affected ${ }^{(6)}$. Another study in rats has investigated the effects of dietary oxidised oils (PV, $94.5 v$ 3.1 meq $\mathrm{O}_{2} / \mathrm{kg}$ ) which had been equalised for FA composition and for tocopherol concentrations by supplementation ${ }^{(7)}$. Body-weight gains and food conversion rates were only slightly lower in rats fed the oxidised oil compared with rats fed the fresh oil. Thus, it was possible to study the effects of lipid peroxidation products without interference due to reduced food intake and growth. In this case, animals fed the oxidised oil had reduced ratios of $20: 4 n-6 / 18: 2 n-6$, $20: 4 n-6 / 20: 3 n-6$ in liver phospholipids and reduced ratios

\footnotetext{
Abbreviations: AA, arachidonic acid; AAFCO, Association of American Feed Control Officials; FA, fatty acid; PL, phospholipid; PV, peroxide value.
}

*Corresponding author: J. E. Bauer, fax +1979 845 6978, email jbauer@cvm.tamu.edu

† Present address: Oxbow Animal Health, 29012 Mill Road, Murdock, NE 68407, USA.

‡ Present address: The Nutro Company, 1550 West McEwen Drive, Franklin, TN 37067 , USA. 
of $20: 4 n-6 / 18: 2 n-6$ in heart PL as well as reductions in other polyunsaturated fat ratios, suggesting a reduced rate of FA desaturation and dramatically reduced hepatic tocopherol concentrations $^{(7)}$.

In nursery pigs, when diet PV exceeded $40 \mathrm{mg} / \mathrm{kg}$, decreased feed intake and growth performance were observed $^{(8)}$. By contrast, calves fed milk replacers containing a PV of $20.6 \mathrm{mg} / \mathrm{kg}$ DM for $31 \mathrm{~d}$ showed no effect on average daily gains, DM intake, or feed efficiency and no evidence of accumulation of peroxides in liver, kidney, heart and adipose tissues $^{(9)}$.

Another consequence of feeding rancid or oxidised fat to animals, including cats, is the appearance of pansteatitis or inflammation of adipose tissues ${ }^{(10)}$. Although fish-containing foods were initially thought to be involved in aetiology ${ }^{(11)}$, there have been numerous reports of pansteatitis in cats fed diets high in rancid polyunsaturated fats from either fish or terrestrial animal products ${ }^{(10)}$. However, the problem especially appears to occur when diet rancidity and antioxidant amounts have been either exhausted or in low concentration ${ }^{(12-14)}$.

Because cats will often refuse foods that have elevated dietary PV, it is unknown what effects chronic feeding of modestly elevated PV diets have on clinico-pathological indices in this species before the development of pansteatitis or related conditions. In the present study, we have taken advantage of a controlled feeding study in which records revealed decreased daily food consumption without weight loss or overt clinical illness in cats fed a diet discovered to have an elevated PV for an extended period of time.

\section{Experimental methods}

The present study was approved by the Texas A\&M University Animal Care and Use Committee (College Station, TX, USA). All cats were housed individually at the Laboratory Animal Research Resources facility, Texas A\&M University according to the American Physiological Society Guidelines for Animal Research and guidelines set forth by Texas A\&M University Care and Use Committee. Physical examinations, complete blood counts, serum biochemistry profiles, and $\mathrm{T}_{3}$ and thyroid-stimulating hormone assays were conducted on each cat to assure that they were clinically normal before the study. Cats (nine animals per group) were maintained on one of three dry extruded diets that were formulated as complete and balanced feeds according to the Association of American Feed Control Officials (AAFCO) nutrient profiles ${ }^{(15)}$. The analysed nutrient composition of the diets ranged from 34.6 to $35.5 \%$ protein, $18 \cdot 2$ to $19 \cdot 95 \%$ fat, $7 \cdot 0$ to $7 \cdot 7 \%$ ash and 1.8 to $2 \cdot 1 \%$ crude fibre on a DM basis with moisture approximately $8 \%$. Diet ingredients (by weight) included Brewers rice $(35.9 \%)$, soyabean protein isolate $(23.3 \%)$, chicken whole carcass and parts (21.6\%), soyabean hulls $(3.67 \%)$, dicalcium phosphate $(2.93 \%)$, coconut oil (2.80\%), flavour coating (1.5\%), beef tallow (0.7\%), potassium chloride (0.65\%), mineral premix (0.34\%), choline chloride (0.32\%), calcium carbonate $(0.29 \%), \mathrm{NaCl}(0.22 \%), \mathrm{D}, \mathrm{L}-\mathrm{methionine}$ $(0 \cdot 18 \%)$, taurine $(0 \cdot 1 \%)$, vitamin premix $(0.07 \%)$ and $50 \%$ vitamin E (0.03\%). The amounts of added dietary fat in each diet were $5 \cdot 24 \%$ safflower oil (diet A), $4 \cdot 85 \%$ coconut oil $+0.5 \%$ borage oil (diet B) and 5.58\% coconut oil (diet C). Thus, the diets differed in FA distribution but contained adequate arachidonic acid (AA, $0.3 \mathrm{~g} / \mathrm{kg}$ ) concentrations and similar antioxidant content added separately as vitamin $\mathrm{E}$ and DL- $\alpha$-tocopherol acetate, the latter was included in the vitamin premix at $90 \mathrm{~g} / \mathrm{kg}$. PV were determined (N.P. Analytical Laboratory, St Louis, MO, USA) and found not to initially exceed $18 \mathrm{meq} / \mathrm{kg}$ dietary fat in any of the diets and all diets were stored at ambient temperature. The diets were fed for $300 \mathrm{~d}$ before spaying all cats (nine animals per group). However, PV analyses of samples obtained the week before spaying at $300 \mathrm{~d}$ revealed a markedly elevated PV of diet A $v$. diets B and C (135 v. 5.80 and $2 \cdot 12 \mathrm{meq} / \mathrm{kg}$ fat, respectively).

Small-volume blood samples were collected via saphenous venepuncture into EDTA-containing tubes on days 0, 140 and 300; serum samples were also collected. Cats ( $n$ 5-6) were sampled daily at approximately 09.00 hours after withholding food for $12 \mathrm{~h}$. Plasma was separated for lipid extraction and total phospholipid (PL)-FA composition was determined via gas capillary chromatography ${ }^{(16)}$. Serum biochemistry profiles were also determined. On day 300, ovariohysterectomies were performed. Cats ( $n$ 5-6) were spayed per day according to established veterinary practice, and were monitored by Laboratory Animal Research Resources veterinarians and staff until full recovery. Uterine, ovarian and subcutaneous adipose tissue samples were collected immediately following ovariohysterectomy procedures. Tissues, upon collection, were stored in $9 \% \mathrm{NaCl}$ ( $\mathrm{NaCl}$ saline solution) on ice during transport to the laboratory and then utilised immediately. Tissues were then homogenised in 40 mm-phosphate buffer ( $\mathrm{pH} 7 \cdot 4$ ) and total lipid extractions, PL fractionation, and FA profiles of this lipid fraction were determined by gas capillary chromatography ${ }^{(16)}$.

All data were analysed using SPSS 16.0 for Windows (SPSS, Inc., Chicago, IL, USA). To determine whether the data were normally distributed, the Shapiro-Wilk test was performed. One-way ANOVA was utilised when data appeared normal to compare the diets with each dependent variable throughout the study. Non-normal data were further analysed using the Kruskal-Wallis test followed by one-way ANOVA. Where significant differences were found, Tukey's multiple comparison tests were performed among the diet groups, with a $P$ value $<0.05$ considered to be statistically significant.

\section{Results}

All cats appeared clinically healthy throughout the study. However, records of food consumption indicated decreased food consumption of diet A beginning at $240 \mathrm{~d}$ in some of the animals. By $280 \mathrm{~d}$, all animals in this group similarly decreased their intake, resulting in an average food consumption decrement of approximately 15\% (Fig. 1). In spite of this decrease, no weight loss had occurred in any of the cats in this group (Fig. 1). Therefore, further investigation was retrospectively focused on whether oxidative deterioration of the diet may have played a role in this observation. When serum biochemistry profiles and complete blood count data were 

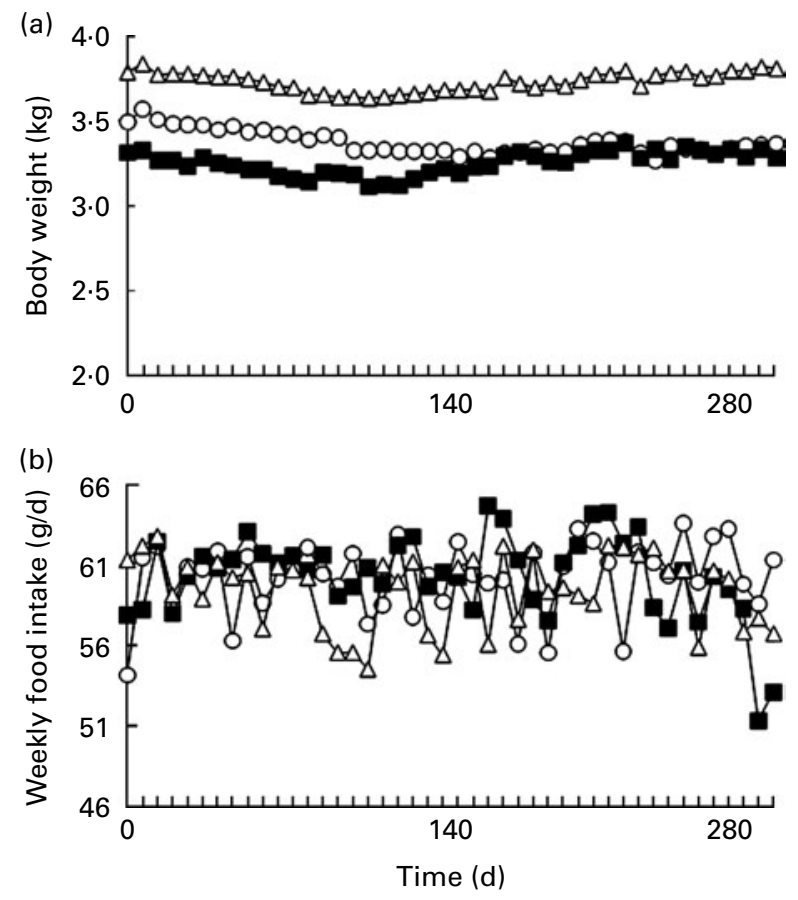

Fig. 1. Average (a) weekly body weights and (b) food consumption during the feeding period. Diet $\mathrm{A}(n 10, \mathbf{\square})$; diet $\mathrm{B}(n 9,0)$ and diet $\mathrm{C}(n 9, \Delta)$.

examined, it was discovered that total plasma protein had been depressed on both days 140 and 300 during the feeding period (Table 1). All other values were within the normal range for cats (data not shown). Among the PUFA, plasma total PL-AA concentrations of cats in group A were also significantly decreased at both these times compared with the other two groups. Mean PL-AA values determined after feeding these diets for $56 \mathrm{~d}$ were as follows: 4.2 (SD 1.3) relative \%, diet $\mathrm{A} ; 6.6$ (SD 0.9) relative $\%$, diet $\mathrm{B}$; and 5.4 (SD 1.2) relative $\%$; diet C. By contrast, total PL-FA profiles of reproductive tissues collected at day 300 revealed no difference among ovarian tissue. AA was greater in uterine tissue from diet B-fed cats but no differences were seen between diets A and
C. Finally, FA analyses of the diets at day 300 showed that diet A was below the minimum AAFCO standards for AA at 0.015\% (minimum for cats: 0.02\%) and a dramatically higher PV compared with the other two diet groups (135.0, $5 \cdot 8$ and $2.15 \mathrm{meq} / \mathrm{kg}$ fat for diets $\mathrm{A}, \mathrm{B}$ and $\mathrm{C}$, respectively).

\section{Discussion}

FA analyses of the diets at day 300 revealed diet A to be below the minimum AAFCO standards for AA with a markedly elevated PV. Because the AA content of diet A was above the minimum requirements initially, loss of this FA due to peroxidation during storage most probably occurred.

It is of interest that total PL-AA content of ovarian tissue homogenates at $300 \mathrm{~d}$ revealed no differences among the groups. By contrast, uterine tissues were significantly higher in AA in diet B-fed cats but no differences were observed between diets A and C. Diet B contained higher amounts of $\gamma$-linolenic acid, and thus may have by-passed the limiting $\Delta$-6 desaturation step leading to a greater rate of AA synthesis in this group. Higher AA was similarly seen in the plasma PL fraction of cats fed diet B after $56 \mathrm{~d}$ of feeding.

Regarding changes in total plasma protein concentrations, an earlier study has shown that rats fed a diet with a PV of approximately $90 \mathrm{meq} / \mathrm{kg}$ at a $10 \%$ level for 4 weeks had altered intestinal absorptive function ${ }^{(6)}$. The rate of in vitro absorption of nutrients, especially sucrose and protein hydrolysate (amino acids), was considerably reduced in this species. Because cats have a higher dietary requirement for protein, it is conceivable that reductions in total plasma protein may have occurred early on when consuming a peroxidised diet. This possibility would explain the decreased plasma total protein observed.

The precise time at which diet A became unacceptable during feeding is unknown. However, we estimate that deterioration occurred between 60 and $140 \mathrm{~d}$ because plasma PL-AA was within our normal colony range (approximately 4-7 relative \%) after $56 \mathrm{~d}$ of feeding this diet, but not at day 140 . The possibility exists that high-linoleic acid-containing diets are

Table 1. Plasma phospholipid (PL), ovarian and uterine arachidonic acid and plasma protein values during the $300 \mathrm{~d}$ feeding period

(Mean values with their standard errors)

\begin{tabular}{|c|c|c|c|c|c|c|}
\hline & \multicolumn{2}{|c|}{ Diet A $(n 10)$} & \multicolumn{2}{|c|}{ Diet B $(n 9)$} & \multicolumn{2}{|c|}{ Diet C $(n 9)$} \\
\hline & Mean & SEM & Mean & SEM & Mean & SEM \\
\hline \multicolumn{7}{|c|}{ Arachidonic acid (day 300 , relative \%) } \\
\hline Plasma PL* & $2 \cdot 1^{\mathrm{a}}$ & 0.8 & $4 \cdot 8^{\mathrm{b}}$ & 1.9 & $4 \cdot 5^{\mathrm{c}}$ & $1 \cdot 1$ \\
\hline Ovary & $10 \cdot 0^{\mathrm{a}}$ & $2 \cdot 3$ & $12 \cdot 6^{\mathrm{b}}$ & 3.0 & $11.5^{\mathrm{a}}$ & 3.3 \\
\hline Uterus & $10 \cdot 3^{a}$ & 0.8 & $15 \cdot 8^{\mathrm{b}}$ & 0.7 & $12 \cdot 1^{\mathrm{a}}$ & 0.7 \\
\hline \multicolumn{7}{|c|}{ Plasma protein $(\mathrm{g} / \mathrm{l}) \dagger$} \\
\hline Day 0 & $61^{a, 1}$ & 6 & $64^{\mathrm{a}}$ & 1 & $63^{\mathrm{a}}$ & 1 \\
\hline Day 140 & $51^{\mathrm{a}, 2}$ & 2 & $60^{\mathrm{a}}$ & 1 & $59^{\mathrm{b}}$ & 1 \\
\hline Day 300 & $51^{a, 2}$ & 2 & $61^{\mathrm{a}}$ & 1 & $61^{\mathrm{b}}$ & 1 \\
\hline
\end{tabular}


more likely to be oxidised requiring more antioxidants. Lower plasma AA may have been the direct result of low dietary AA content and peroxidation. However, determination of plasma $\mathrm{AA}$ in combination with a reduction in plasma protein may serve as a biomarker of diet peroxidation in cats before feed refusal, weight loss or tissue depletion.

\section{Acknowledgements}

J. E. B. holds the Mark L. Morris Professorship of Clinical Nutrition at Texas A\&M University and has received funding from several pet food companies. Funding was provided by the Mark L. Morris Professorship of Clinical Nutrition. J. E. B. designed the study; A. C. and Y. M. designed the study and performed the research; K. B. provided the technical assistance.

\section{References}

1. Vilas NN, Bell RR \& Draper HH (1976) Influence of dietary peroxides, selenium and vitamin $\mathrm{E}$ on glutathione peroxidase of the gastrointestinal tract. J Nutr 106, 589-596.

2. Reddy K \& Tappel AL (1974) Effect of dietary selenium and autooxidised lipids on the glutathione peroxidase system of gastrointestinal tract and other tissues in the rat. J Nutr 104, 1069-1078.

3. Aw TY, Williams MW \& Gray L (1992) Absorption and lymphatic transport of peroxidised lipids by rat small intestine in vivo: role of mucosal GSH. Am J Physiol 262, G99-G106.

4. Mézes M, Virág Gy, Barta M, et al. (1996) Effect of lipid peroxide loading on lipid peroxidation and on the glutathione and cytochrome systems in rabbits. Acta Vet Hung 44, 443-450.
5. Slim R, Nicholas KN, Toborek M, et al. (1995) Hepatic susceptibility to oxidative stress in rabbits fed different high-fat diets. In Proceedings of the 95th Experimental Biological Congress. Professional Research Scientist, 1995 August, Atlanta, GA, USA, Part I, Abstract 2454.

6. Behniwal PK, Soni GL, Vadhera S, et al. (1993) In vitro absorption of nutrients from small intestine of rats fed peroxidized oil. Indian J Exp Biol 7, 658-659.

7. Eder K (1999) The effects of a dietary oxidized oil on lipid metabolism in rats. Lipids 34, 717-725.

8. DeRouchey JM, Hancock JD, Hines RH, et al. (2004) Effects of rancidity and free fatty acids in choice white grease on growth performance and nutrient digestibility in weanling pigs. J Anim Sci 82, 2937-2944.

9. Jenkins KJ \& Emmons DB (1984) Tolerance of calves to fat peroxides in milk replacer. J Dairy Sci 67, 592-597.

10. Watson ADJ, Porges WL, Huxtable CR, et al. (1973) Pansteatitis in a cat. Australian Vet J 49, 388-392.

11. Coffin DL \& Holzworth J (1954) 'Yellow fat' in two laboratory cats: acid-fast pigmentation associated with a fish-base ration. Cornell Vet 44, 63-71.

12. Cordy DR (1954) Experimental production of steatitis (yellow fat disease) in kittens fed a commercial canned cat food and prevention of the condition by vitamin E. Cornell Vet 44, 310-318.

13. Munson TO, Holzworth J, Small E, et al. (1958) Steatitis ('yellow fat') in cats fed canned red tuna. J Am Vet Med Assoc 133, 563-568.

14. Niza MMRE, Vilela CL \& Ferreira LMA (2003) Feline pansteatitis revisited: hazards of unbalanced home-made diets. J Feline Med Surg 5, 271-277.

15. Association of American Feed Control Officials (AAFCO) (1998) Harrisburg, PA: Official Publication.

16. Angell R, Mitsuhashi Y, Bauer JE, et al. (2009) Plasma LCAT activity and lipid subfraction composition in obese beagles undergoing weight loss. Lipids 44, 415-424. 